\title{
Analysis of relation between edging ratio and deformation work done in pre-forming of workpiece by bulk buckling
}

\author{
Volodymyr Kukhar ${ }^{1,{ }^{*}, \text { Elena } \text { Balalayeva }}{ }^{2}$, Andrii Prysiazhnyi ${ }^{1}$, Oleg Vasylevskyi ${ }^{1}$, and \\ Iryna Marchenko ${ }^{2}$ \\ ${ }^{1}$ Pryazovskyi State Technical University, Department of Metalforming, Universytets'ka, 7, Mariupol, \\ 87500, Ukraine \\ ${ }^{2}$ Pryazovskyi State Technical University, Department of Information Science, Universytets'ka, 7, \\ Mariupol, 87500, Ukraine
}

\begin{abstract}
The results of studies of energy-power indices (contact face pressure, work of deformation) during upsetting with buckling of relatively high workpieces with upsetting ratio 3.5 to 6.0 are summarized in the paper. The relation between work of deformation at the bulk buckling and edging ratio, and similar shape ratios was established. The results are shown that buckling pass is an energy-efficient way of workpieces shaping for bent forgings or dual-forming of some products and belong to the class of dieless (impression-free) bulk pre-forming process.
\end{abstract}

\section{Introduction}

Upsetting and bending are the most common operations in press-forging industry. Upsetting is mostly performed as pressing between two flat dies, although the dies should still be regarded as a pressing deforming tool that has contoured working faces or impressions which provide the necessary shape to the product after pressing. The processing of cylindrical workpieces by not contoured dies in manufacturing is more common. Its purpose is descaling, increasing of workpiece diameter for subsequent cogging, swaging, impression or die-forging of forgings with a round in plan view area cross section, improving the inner metal structure and growth of new fine grains [1-2]. Bending is used for bulk and sheet metal forming, and this operation is usually carried out with application of contoured dies, forming rolls or bending machines [3].

We propose and investigate a brand new bulk forming process, such as pre-forming of workpiece for subsequent open die or closed die forging by upsetting of billet with large ratio of height $L_{0}$ to diameter $D_{0}$ (upsetting ratio $m_{0}=L_{0} / D_{0}=3.5 \ldots 6.0$ or more), followed by buckling. Bulk forming of workpiece by upsetting with buckling is performed as a single-stroke process and one such operation combines at least three: descaling, bending and redistribution of metal along the length of a workpiece (edging, fullering or gathering - at drop-forging). Practical application of such operations like forming of

* Corresponding author: kvv.mariupol@gmail.com 
forgings with a bent axis or dual forming [4] showed fine results in saving of metal (at least $20 \%$ ), however, the energy-power modes of process, stored energy and the energy (work) expenditure for the bulk buckling remain unexplored. In addition, the relation of the amount of expended and stored energy to the edging ratio and other indices of the shaping of the workpieces are unknown. The investigation of energy consumption and its comparison with the edging ratios as a measure of workpiece pre-forming is relevant for the selection of manufacturing equipment, design of dies and evaluation of items of energy costs in the production of forgings.

To the strain of thin-walled shells, columns and rods has a sufficient number of modern fundamental studies [5-6], which, unfortunately, can not be used to predict the bulk shape changes and determining the stored and consumed energy for its implementation at upsetting with buckling due to a discrepancy between geometric and boundary conditions. The results are applicable only to the elastic region and it is impossible to estimate the variation of the energy-power behaviour and shape indices of the rods and shells experiencing the plastic buckling.

Buckling of aircraft panels under static loads to track the appearance of fatigue cracks was studied in the work [7]. An important factor is the shape factor, namely the effect of "side-to-thickness ratio" and for functionally structured materials for support plates production, to which specific requirements are imposed [8]. Positive use of the phenomenon of buckling is observed by the researchers in the simulation and experiments on the production of two-rib plates [9]. However, this effect relates to a horizontally placed workpiece in the closed die with the application of punch power load to the middle of workpiece.

The pre-forming of workpieces by upsetting with buckling was suggested in paper [4] as one of the options for impression-free shaping of workpieces for subsequent open die or closed die forging. There thermal pre-forming (thermal intensification with a given gradient of heating) of workpieces [10], and rupture of workpieces, carried out with the localization of the heated part [11], are referred to an impression-free forging processes too. Modern technologies of incremental forming without dies are carried out with a pencil-like tool with local and sequential forming of the profile on the sheet blank using CNC machines [12]. Such processes are not referred to bulk forming and are carried out in a cold state. The elimination of distortions of the press slider is an important issue in workpieces pre-forming by bulk-buckling and ensured by the use of "press-die" system compensators [13-14].

Information on the relation between mechanical work of deformation and edging ratio or other shape indices for bulk buckling of upset workpieces that are completely in the plastic state with a continuous and uneven increase in the cross-section is absent, which causes the scientific novelty of the problem.

\section{Methodology and materials}

The buckling, accompanied with redistribution of metal along the bended workpiece's axis should be considered to be one of the most efficient methods of impression-free preforming that has not been thoroughly investigated yet. On the basis of upsetting workpieces with round cross-section with the ratio of height $\left(L_{0}\right)$ to diameter $\left(D_{0}\right)$ exceeding $3.5 \mathrm{a}$ series of stamping processes of forgings with bent axis (Figure 1a,b) were improved with metal saving amounting to $18 \ldots 41 \%$, increase in productivity and reduction in consumption of stamped steel.

Still, for a complete evaluation of advantages of the technological decisions, including the ones at the design stage the analysis of energy consumption (or work) for forming at profiling operations seems to be quite advisable. 
Ratios of workpiece's linear dimensions prior to and after pre-forming, evaluated by geometrical methods at the experiments of found by simulation $\left(a, b, q, c, l, L_{k}, B\right.$, $H_{k}, r, h, \varphi_{c}-$ controlled dimensions according to the Figure 1c) are considered to be dimensionless forming indices:

$$
k_{1}=D_{\min } / D_{0} ; k_{2}=D_{\max } / D_{0} ; K=D_{\max } / D_{\min }=k_{2} / k_{1},
$$

Where $D_{\max }=1.13 \sqrt{\pi \cdot(\bar{c} / 2) \cdot(\bar{l} / 2)}$ and $D_{\min }=1.13 \sqrt{\pi \cdot(\bar{a} / 2) \cdot(\bar{b} / 2)}$, here $\bar{a}, \bar{b}, \bar{c}, \bar{l}$ are average statistical values of measurements according to the measuring scheme (see Figure 1c).

The main idea of this investigation is to develop scientific conceptions regarding the fact that the value of mechanical work of deformation is proportional to the realized shape indices of a pre-formed workpiece, including edging ratio $\left(K_{e d}\right)$. That index is calculated as a ratio of maximum area $\left(F_{\max }=\pi \cdot(\bar{c} / 2) \cdot(\bar{l} / 2)\right)$ of cross-section of the profiled workpiece to its average area $\left(F_{\text {mid }}=\pi \cdot(\bar{a} / 2) \cdot(\bar{b} / 2)\right)$, defined by dividing the volume $V_{\text {work }}$ by the length of deflection of the workpiece $L_{k}$ (Figure 1c). Hence, we obtain $K_{e d}=k_{2}^{2}(1-\delta)$, where $\delta=\left(L_{0}-L_{k}\right) / L_{0}$ - relative shortening, also represented by $\delta\left(m_{0} ; \varepsilon_{y}\right)$ function. Evidently, the square value of the ratio of linear dimensions, particularly, macro-indices $\left(k_{1}\right)^{2},\left(k_{2}\right)^{2}$ and $K^{2}$, has also a proportional connection with the value of work, consumed on forming. Dependencies $k_{1}\left(m_{0} ; \varepsilon_{y}\right)$ and $k_{2}\left(m_{0} ; \varepsilon_{y}\right)$, where $\varepsilon_{y}=\left(L_{0}-H_{k}\right) / L_{0}$, were preliminarily found.

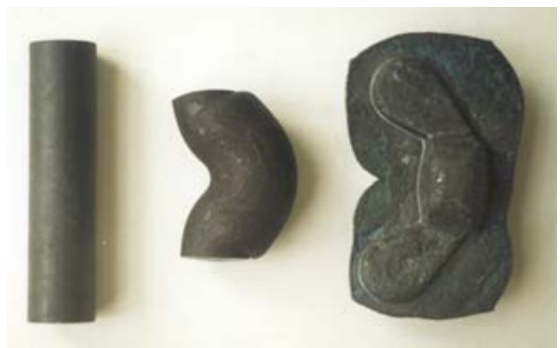

(a)

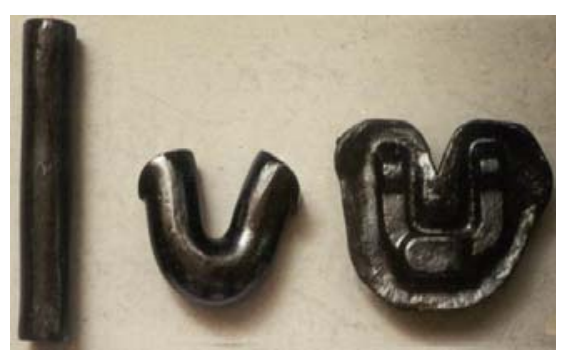

(b)
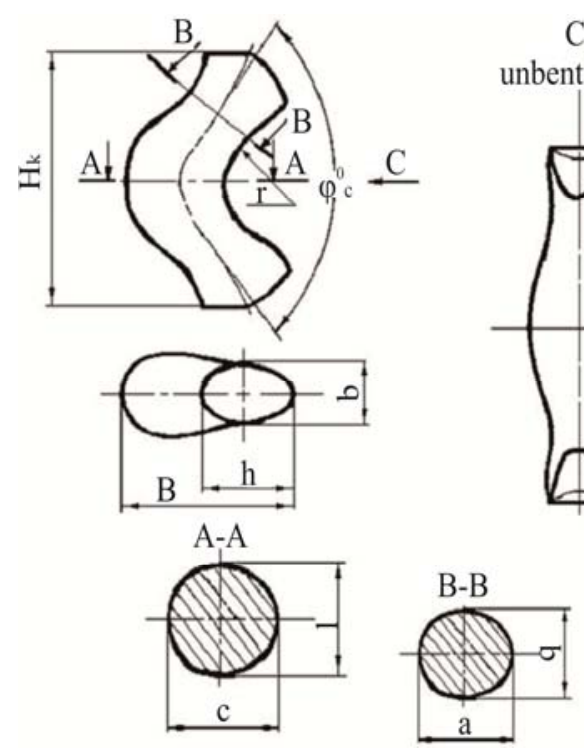

(c)

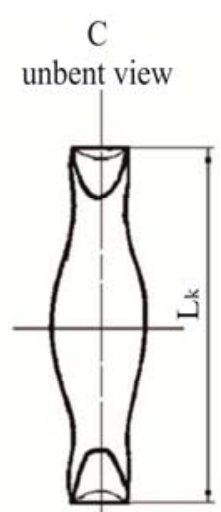

Fig. 1. Buckling in die-forging processes of forgings of fly-nuts type (a), sliding fork type (b), and the scheme of dimensions control (c).

The work consumed on forming is connected with power dissipation due to internal deformation, friction, internal velocity discontinuity and external traction force [15-16]. 
Electric power expenses are losses that proportional to expenses on mechanical forming of workpieces [17-18]. As upsetting ratio of workpieces grows the influence of friction forces is minimized (at values $m_{0}>3.5$ they can be neglected), while free edging and fullering effect are influenced by a complicated forces distribution in workpiece, rather than interface and "die-material" condition. Energy (work) consumed on deformation is consumed on forming and heating of material [19-20], hardening properties of which depend on strain range and strain rate. It was revealed in the analysis [18-21] that the work done was the integral of the force parameters and distance parameters. Force parameters were defined experimentally [22], by bringing them to pressure value $(p)$ by dividing the value of load by the area of workpiece cross-section, while distance parameters were brought to strain.

For a pass to characteristic of the process type, that does not depend on the material properties the reduced pressure $\left(\eta_{\sigma}\right.$, as relative specific load) was calculated by dividing the pressure at buckling by flow stress value, corresponding to deformation conditions.

Complete $(A)$ and specific work ( $A_{S}$ ) of forming is evaluated as:

$$
A=V_{\text {work }} \cdot p_{\text {mid }} \cdot \varepsilon, \text { and } A_{s}=p_{\text {mid }} \cdot \varepsilon
$$

Where $p_{\text {mid }}$ is an average pressure until the strain range $\varepsilon$, which, according to the principle of shifted volume for deflected workpiece, is understood to be equal to $\delta$ (i.e. $\varepsilon=\delta)$.

Then:

$$
\begin{gathered}
p_{\text {mid }}\left(m_{0}, \varepsilon_{y}\right)=\frac{1}{\delta\left(m_{0}, \varepsilon_{y}\right)} \int_{0}^{\delta\left(m_{0}, \varepsilon_{y}\right)} p\left(m_{0}, \varepsilon_{y}\right) d \varepsilon_{y}= \\
=\frac{1}{\delta\left(m_{0}, \varepsilon_{y}\right)} \int_{0}^{\delta\left(m_{0}, \varepsilon_{y}\right)} \eta_{\sigma}\left[m_{0}, \delta\left(m_{0}, \varepsilon_{y}\right)\right] \cdot \sigma_{s}\left[\delta\left(m_{0}, \varepsilon_{y}\right)\right] d \varepsilon_{y},
\end{gathered}
$$

Where $p\left(m_{0}, \varepsilon_{y}\right)$ и $\eta_{\sigma}\left\lfloor m_{0}, \delta\left(m_{0}, \varepsilon_{y}\right)\right\rfloor$ - the functions of pressure changes and reduced pressure respectively [22], while $\sigma_{s}\left[\delta\left(m_{0}, \varepsilon_{y}\right)\right]=\sigma_{s}(\varepsilon, t, \xi)$ - the dependence of flow stress of material upon the degree of strain range $(\varepsilon)$, temperature $(t)$ and strain rate $(\xi)$, defined, for instance, by approximating the data of reference book [21].

\section{Results and discussion}

By applying the data [21] for hot deformation $\left(t=1100{ }^{\circ} \mathrm{C}, \xi=0.5 \mathrm{~s}^{-1}\right)$ of steel St.3 grade $(\mathrm{Fe} \approx 97 \%, \mathrm{C}=0.14 \ldots 0.22 \%, \mathrm{Si}=0.15 \ldots 0.3 \%, \mathrm{Mn}=0.4 \ldots 0.65 \%, \mathrm{Ni}<0.3 \%, \mathrm{~S}<0.05 \%$, $\mathrm{P}<0.04 \%, \mathrm{Cr}<0.3 \%, \mathrm{~N}<0.008 \%, \mathrm{Cu}<0.3 \%, \mathrm{As}<0.08 \%$ ), integral value of pressure (Figure $2 \mathrm{a}$ ) and specific deformation work (Figure $2 \mathrm{~b}$ ) at upsetting with buckling were evaluated in accordance with the methods described above.

The correlation of shape indices, which are squared (are raised to the second degree), and edging ratio of workpieces with the mechanical work to be done for reaching their defined values is showed in Figure 3. 


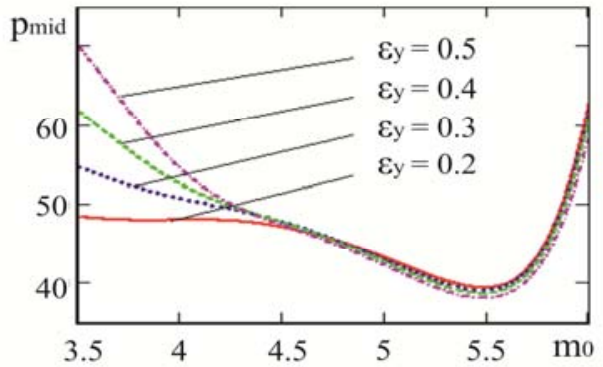

(a)

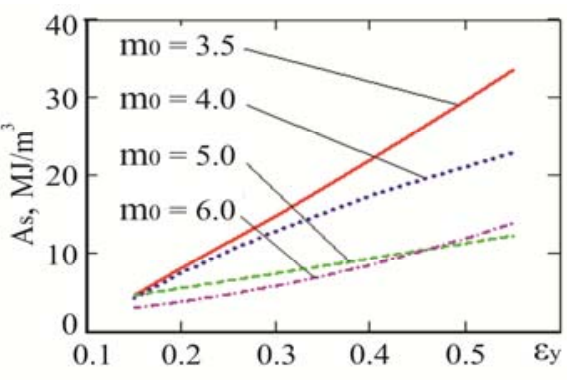

(b)

Fig. 2. Evaluated dependencies of average pressure values (a) and specific work of pre-forming (b) at buckling.

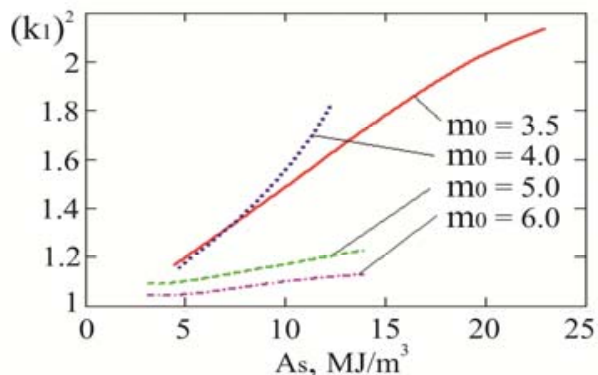

(a)

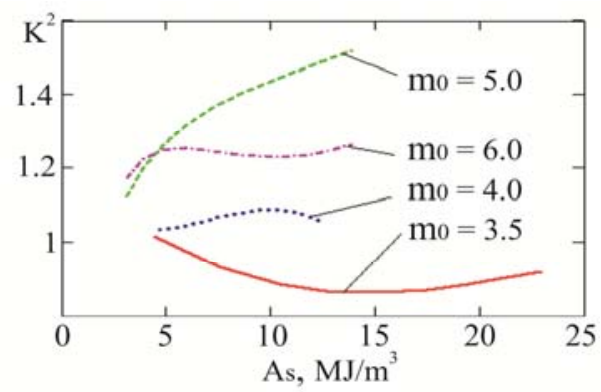

(c)

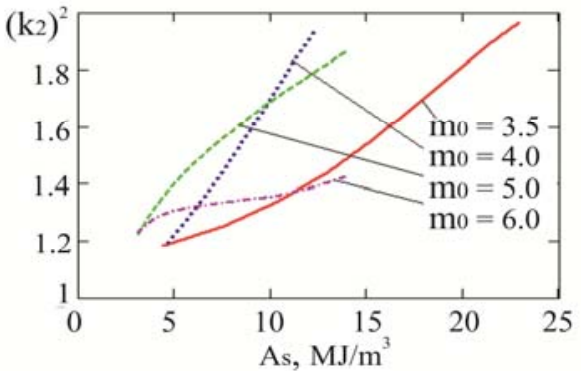

(b)

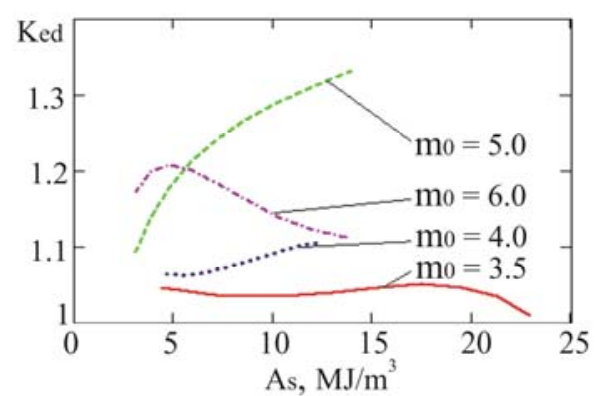

(d)

Fig. 3. Dependence of forming macro-indices upon specific deformation work:

(a) $-\left(k_{1}\right)^{2}=f\left(A_{s} ; m_{0}\right) ;(\mathrm{b})-\left(k_{2}\right)^{2}=f\left(A_{s} ; m_{0}\right) ;(\mathrm{c})-K^{2}=f\left(A_{s} ; m_{0}\right) ;(\mathrm{d})-K_{e d}=f\left(A_{s} ; m_{0}\right)$.

Thus, evaluation of energy consumption of buckling at realization of certain shape macro-indices was executed. Future prospect may be correlation of forming work and energy consumption on die-forging or die pre-forming.

\section{Conclusions}

Summarized were the results investigations of alternations of energy-power parameters (contact face pressure, work of deformation) during upsetting of relatively high workpieces with upsetting ratio 3.5 to 6.0 , it being accompanied with their buckling.

Types of regular correlations between work of deformation at buckling and shape indices of pre-formed workpiece were defined. To be more precise, on the basis of regularities of alternations of energy-power modes and defining the strain range through 
shifted volumes the forming work at pre-forming of workpieces by bulk buckling was evaluated, required for reaching macro-indices and edging ratios that characterize the rate of workpieces pre-forming for their subsequent forging in die impressions.

The results prove that pre-forming operation by upsetting with buckling of workpieces is a power-saving method of shaping for forgings with bended axis or dual forming of certain products and belong to the class of impression-free bulk pre-forming process. The prospect of the research application is to compare the energy costs for obtaining the same value of the edging ratio by impression and impression-free forging method.

\section{References}

1. V. V. Kukhar, O. V. Vasylevskyi, Metallurgical and Mining Industry 3, 71 (2014)

2. V. Kukhar, V. Artiukh, A. Butyrin, A. Prysiazhnyi, Advances in Intelligent Systems and Computing 692, 201 (2018)

3. T. Altan, A.E. Tekkaya, Sheet Metal Forming: Processes and Applications (ASM International, Ohio, 2012)

4. V. Kukhar, V. Burko, A. Prysiazhnyi, E. Balalayeva, M. Nahnibeda, East-European Journal of Enterprise Technology 3/7(81), 53 (2016)

5. J. Singer, J. Arbocz, T. Weller, Buckling Experiments, Basic Concepts, Columns, Beams and Plates: Vol. 1 (Hoboken, Wiley, 2007)

6. J. G. Teng, J. M. Rotter, Buckling of Thin Metal Shells (CRC Press, 2006)

7. D. Quinn, A. Murphy, L. Cervi, Proc. Inst. Mech. Eng. G 225(7), 791 (2011)

8. B. Sidda Reddy, J. Suresh Kumar, C. Eswara Reddy, K. Vijaya Kumar Reddy, Journal of Composites 2013, 808764 (2013)

9. A. Dziubińska, A. Gontarz, Metalurgija 54(3), 555 (2015)

10. V. Kukhar, V. Artiukh, O. Serduik, E. Balalayeva, Procedia Engineering 165, 1693 (2016)

11. V. V. Kukhar, Metallurgical and Mining Industry 6, 122 (2015)

12. A. Kochan, Assembly Automation 21(4), 321 (2001)

13. V. Kukhar, E. Balalayeva, O. Nesterov, MATEC Web of Conferences 129, 01041 (2017)

14. E. Balalayeva, V. Artiukh, V. Kukhar, O. Tuzenko, V. Glazko, Advances in Intelligent Systems and Computing 692, 220 (2018)

15. S. Solhjoo, Preprint arXiv: 1402.6749 (2014), http://arxiv.org/abs/1402.6749

16. V .I. Kaplanov, A. G. Prisyazhnyi, Steel in Translation 38(9), 714 (2008)

17. V. V. Burlaka, S. V. Gulakov, MATEC Web of Conferences 113, 01005 (2017)

18. S. K. Chemann, H. Wagner, M. Schwabe, D. Bedorf, W. Arnold, K. Samwer, Metallurgical and Materials Transaction A 45(5), 2389 (2014)

19. S. Kalpakjian, S. R. Schmid, C.-W. Kok, Manufacturing Processes for Engineering Materials (Pearson Education, Inc., NJ, 2008)

20. G. A. Orlov, Metallurgist 58(11-12), 1001 (2015)

21. P. I. Polukhin, G. Ya. Gun, A. M. Galkin, Soprotivlenie plasticheskoi deformatsii metallov i splavov. Spravochnik (Plastic flow stress of metals and alloys. Handbook), (Moscow, Metallurgy, 1983, in rus.)

22. V. Kukhar, V. Artiukh, A. Prysiazhnyi, A. Pustovgar, E3S Web of Conference 33, 02031 (2018) 